\title{
An example of how to build conservation evidence from case studies:Fire and raking to enhance Pulsatilla vernalis populations
}

\author{
Annelie Sandström, Brita M. Svensson and Per Milberg \\ Journal Article
}

\section{Tweet}

N.B.: When citing this work, cite the original article.

Original Publication:

Annelie Sandström, Brita M. Svensson and Per Milberg, An example of how to build conservation evidence from case studies:Fire and raking to enhance Pulsatilla vernalis populations, Journal for Nature Conservation, 2017. 36 pp.58-64.

http://dx.doi.org/10.1016/j.jnc.2017.02.005

Copyright: Elsevier

$\underline{\text { http://www.elsevier.com/ }}$

Postprint available at: Linköping University Electronic Press

http://urn.kb.se/resolve?urn=urn:nbn:se:liu:diva-134651

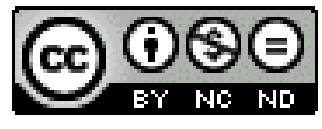

1.U. UNNGERSGS 


\section{An example of how to build conservation evidence from case studies: fire and raking to enhance Pulsatilla vernalis populations}

Anneli Sandströmª, Brita M. Svensson ${ }^{\mathrm{a}}$, Per Milberg ${ }^{\mathrm{b}}$

${ }^{a}$ Department of Plant Ecology and Evolution, Evolutionary Biology Centre, Uppsala University, Norbyvägen 18D, SE-752 36 Uppsala, Sweden

${ }^{\mathrm{b}}$ IFM Biology, Conservation Ecology Group, Linköping University, SE-581 83 Linköping, Sweden

Corresponding author: Per Milberg, IFM Biology, Linköping University, SE-581 83 Linköping, Sweden; permi@ifm.liu.se; +46 705173100 


\begin{abstract}
Can data collected by practitioners during practical conservation work be used as decision support? To find out, we used unpublished data from attempts to enhance populations of the vascular plant Pulsatilla vernalis in Sweden. About half of the 50 located cases had generated data useful for metaanalysis. We could show that burning had a positive effect while mechanical disturbance had negligible effects on number of plants in short-term follow-ups. Furthermore, we suggest that follow-up variables related to flowering are inferior for monitoring intervention success as flowering varies greatly between years. In the broader context, our example shows that simple records from practical conservation work can be a rich source of information. It was also obvious that there is great potential for more useful evidence by making just small improvements in field protocols, documentation, and archiving. Finally, we suggest that biologists and researchers need to develop an appreciation of "different levels of evidence", and that in circumstances where we lack relevant experiments or observational studies, case studies might be useful for improving interventions.
\end{abstract}

\title{
Introduction
}

The process of implementing evidence-based conservation has begun worldwide and guidelines have developed how to organise the writing of systematic reviews (Stewart et al. 2005; Pullin \& Stewart 2006) and how to summarise and analyse multiple independent studies using meta-analysis (Koricheva et al. 2013). Also, mechanisms how to improve the information flow between researchers, decision-makers and practitioners have been suggested (Pullin \& Knight 2003). Using these guidelines, we could expect a steady increase in the number of systematic conservation-focused reviews that meticulously follow the protocol inherited from evidence-based medicine. However, although evidence-based conservation has much appeal to all parties involved, primary research will never fulfil the research needed to support decision-makers (Milberg 2014). In addition, a large part of the vast plethora of conservation problems will never be the subject of a systematic review. One problem, often pointed out in systematic reviews, is that data for metaanalysis often is missing, or presented in inappropriate detail. For example, Stewart et al. (2009) reported that despite having 179 studies using the same type of intervention only 17 had enough data to be included in the meta-analysis. Furthermore, with the great diversity of conservation problems, only a small fraction could ever have a proper evidence base: there is simply too little information in the scientific literature. Hence, the practitioner often has limited use of the scientific literature and instead has to rely on "expert opinion” - own or others - or logic inference.

What to do to help build conservation evidence that matters for practitioners? In this contribution, we suggest using evidence of lower quality, and a more relaxed protocol for compiling information to be used as decision support. Often there is some type of follow-up activity when conservationists invest in an intervention to restore a habitat or enhance an endangered species. Rarely, however, do these data contribute 
to no more than local "expert opinions" and because of low statistical power to reject the null hypothesis of "no effect", the results are often inconclusive. We surveyed and compiled information on the outcomes from practical conservation work, none of which had been published. In the hierarchy of quality evidence by Pullin \& Knight (2003), such information would be close to lowest level, level IV. The information would also be somewhat comparable with "expert opinion" (for which there is no data recorded as support) but clearly below the case study/report (which is properly documented and published). The example we chose was conservation efforts in Sweden for the plant species Pulsatilla vernalis, knowing that its steady decline had spurred several local initiatives to promote remaining populations. This species is a conservation priority in several other countries as well (Betz et al. 2013).

More specifically, we wanted to evaluate the effects of burning and mechanical disturbance in promoting populations of $P$. vernalis. Is there an effect discernible, and if so is one method better than the other? More generally, we wanted to evaluate the usefulness of simple records from practical conservation work. Is it at all a useful source of information as decision support or for identifying areas in need of research?

\section{Materials and Methods}

\section{Study organism}

Pulsatilla vernalis (L.) Mill. belongs to the family Ranunculaceae and is a hemicryptophytic perennial herb found in central Europe (Hultén \& Fries 1986; Ronikier et al. 2008) and in the boreo-nemoral and southern boreal zones in Sweden (Ståhl \& Edqvist 2006). The species seems to have a preference for sandy soils (Grzyl et al. 2013) and the habitats of P. vernalis in Sweden are open pine forests, esker slopes, pastures and heathlands (Lindell 2001). Åström \& Stridh (2003) reported that P. vernalis in 2002 was considered lost or not found in 45\% of previously known Swedish sites since 1965.

The decline can be explained both by an actual destruction of sites through forestry and extraction of gravel, and by a degradation of still existing sites through eutrophication and the abandonment of outfield (forest) grazing, resulting in encroachment (Stridh et al. 2016). There has also been a general increase in standing volume of timber in Swedish forests (Hedwall et al. 2013), i.e., the forests have become darker. Pulsatilla vernalis is considered sensitive to competition from e.g., graminoids, dwarf shrubs, mosses and lichens suppressing plant growth and regeneration (Stridh et al. 2016; Ståhl \& Edqvist 2006; Zielińska et al. 2016). Site degradation can also be related to a reduced fire frequency, both natural fire outbreaks and man-induced through an earlier slash-and-burn culture, and the former practice of preparing clearcuts for regeneration through burning (Stridh et al. 2016; Ståhl \& Edqvist 2006). With its rapid decrease, showy flowers and early flowering, it has become something of a flagship species for the conservation of both heathlands and dry pine forests. 
Pulsatilla vernalis is classified as EN (endangered) in the Swedish Red List (ArtDatabanken 2015). The Swedish Species Action Plan (Stridh et al. 2016) provides a specific management plan aimed at conservation organisations, e.g., county administration boards, on how to secure and manage known sites of the species. Today, recommended conservation actions involve controlled burning, reintroducing forest grazing and different kinds of mechanical disturbances, e.g., raking of ground vegetation and clearing of trees and shrubs and hand-sowing on open mineral soil (Stridh et al. 2016). These actions have, however, never been evaluated as to their efficiency.

\section{Tracking and compiling the data}

The first step involved getting in contact with those presently or previously involved in the practical work that had been conducted (Figure 1). One of us (AS) therefore contacted conservation managers at county administration boards as well as county coordinators within the on-going citizen-science project of the threatened Swedish flora (Flora Guardians, http://svenskbotanik.se/floravaktarna/). Using these persons as a springboard, the information network expanded and in the end involved conservation efforts regarding $P$. vernalis among county administration boards, municipalities, companies, NGOs as well as private persons. In the following we will refer to these collectively as informants, as they were the ones providing information and data on their efforts and their outcome.

The second step involved selecting among these conservation efforts (Figure 1), using the following inclusion criteria:

I. the conservation action should have constituted an intervention directly targeting $P$. vernalis or affecting a known site of $P$. vernalis, and

II. the intervention should have affected or been distributed throughout the entire $P$. vernalis population more or less equally, and

III. the P. vernalis population should have been monitored, providing population data both before and after the intervention.

Monitoring data were primarily extracted from the Swedish Species Gateway (www.artportalen.se, version 26 January 2012) but complemented with inventories done by county boards, personal notes or recalled observations from botanists, conservation managers and land owners, not registered in the Species Gateway. If several people had been involved in the documentation at a particular site, the informants were further inquired to ensure consistency. The gathering of data sets was made from January to March 2012.

As expected, the cases involved several types of interventions, and combinations thereof. The population data were of different kinds; (e.g., number of clusters of plants, flowering clusters, and flowers). Therefore, the third step involved identifying suitable outcomes from the gathered data sets. Interventions generally fell 
in two different groups, “disturbance treatments" and "sowing treatments”, and here we present results for the first of these. Information on sowing treatments can be found in Sandström (2013) and Sandström et al. (2014).

We investigated the following interventions and site characteristics: habitat type (coniferous forest versus heathland) and intervention type (burning or a combination of burning and mechanical disturbance versus solely mechanical disturbance). Three types of population data were distinguished and separated: number of clusters, flowering clusters, and flowers. Depending on the individual case study, the number of $P$. vernalis clusters could reflect number of plants, rosettes or compact groups of $P$. vernalis (number of rosettes being the most common).

\section{Statistical analyses}

The effects of different interventions and site characteristics were analysed using meta-analyses, examining changes on the three outcomes through time. The effects were evaluated comparing data from the same year as the intervention (the "pristine number") and with data recorded one, two and three years after the intervention (the "affected numbers"). Due to insufficient or short-time follow-ups, comparisons were not possible beyond three years. The meta-analyses were performed using the effect sizes event rate (ER) and odds ratio (OR). Event rate was calculated having non-events as the pristine number of $P$. vernalis and events as the affected number (applied to all three types of population data). For odds ratio, the pristine and affected numbers were represented by control and treated, while non-events and events were represented by the number of flowering and not flowering $P$. vernalis clusters, respectively. The size of a case study is represented by the number of clusters, number of flowering clusters, or number of flowers before and after the intervention. Event rates and odds ratios were logit and log transformed, respectively (Eq. 1 and 2). Logit event rates $>0$ and $<0$ (corresponding event rates being $>0.5$ and $<0.5$ ) mean that an increase or a decrease occurred after the intervention, respectively. Log odds ratios $>0$ or $<0$ (corresponding odds ratios being $>1$ or $<1$ ) mean that the proportion of flowering clusters (the number of flowering clusters in relation to the total number of clusters) increased or decreased after the intervention, respectively. By back-transforming logit event rate and up-scaling it with the total number of non-events and events, the change in P. vernalis after an intervention could be expressed as percentages - the same is not possible for log odds ratio (Agrawal 2005). The analyses were performed using a random effect model since the "true" effect size were expected to differ among case studies, e.g., as a result of different site and intervention characteristics not considered in the analyses (Gurevitch \& Hedges 1999). In general the random effect model is preferred within ecology (e.g., Gates 2002; Koricheva et al. 2013; Thompson \& Higgins 2002). All analyses were done using the software Comprehensive Meta-Analyses version 2.

Logit $($ ER $)=\ln ([$ events/(events+non-events) $] /[1$-events/(events+non-events) $])$ 
$\ln (\mathrm{OR})=\ln ($ treated_events $\times$ control_non-events/treated_non-events $\times$ control_non-events) $($ Eq. 2)

\section{Results}

The data search resulted in up to 23 case studies, depending on which population parameter that was analysed, with sufficient data to be analysed, while 26 cases had to be excluded. Excluded cases either had inconsistent inventory units or lacked documented inventories in the same year as the intervention or in the following years. The interventions were conducted between 1989 and 2010.

\section{Number of clusters}

There was substantial variation in the response of $P$. vernalis among the 19 cases involving burning or mechanical disturbance one to three years after the intervention (Figure 2a). Burning generally had a positive effect on number of clusters, the effect lasted up to two years after the intervention (Figure 2b). Mechanical disturbance, in contrast, resulted in a small decrease in the number of clusters, particularly after two years (Figure 2b). Pulsatilla vernalis clusters subjected to burning showed a tendency to fare a better outcome in heathland communities compared to within coniferous (Pinus sylvestris) forests, as illustrated by the larger overall effect size and somewhat overlapping confidence intervals (Figure 2c).

\section{Flowering}

Flowering overall displayed varying results, illustrated by large confidence intervals (Table 1). In populations subjected to burning, the number of flowering clusters increased significantly, but was based only on a single case (logit ER $=1.421$, Table 1 ). In contrast, where the ground surface had been disturbed mechanically there was only a small and non-significant increase (logit ER $=0.21$, Table 1 ). The overall outcome one year after an intervention did not differ between the coniferous forests and heathlands (data not shown; there were no comparative data available beyond the 1-year follow-up).

Regarding the proportion flowering $P$. vernalis clusters (number of flowering in relation to the total number of clusters, i.e., log OR of flowering clusters), there was no clear difference during the first year between populations subjected to burning or to mechanical disturbance. The proportion flowering clusters increased in both cases but with large variation (Table 1) and also overlapping confidence intervals.

Also the number of flowers in each population varied greatly with no significant effects (Table 1). It was noteworthy that as the number and proportion of flowering clusters increased after 1 year (strongly and weakly, respectively), the number of flowers decreased, albeit weakly so (Table 1). 


\section{Discussion}

We selected Pulsatilla vernalis as an example for this study as we knew many attempts had been made to actively secure and promote its Swedish populations. The most common interventions we came across regarded disturbance in the form of burning, raking, thinning of trees and shrubs, and re-introducing forest grazing. Also, seed sowing and planting of potted plants have been used. Still, we were surprised by both the large number of cases, and that data had been recorded that, in many cases, could be subjected to metaanalysis. Simultaneously, we had to reject many data sets and available case studies, most often because they lacked repeated or consistent inventory records.

By analysing two intervention types (burning and mechanical disturbance) within two habitat types (heathland and coniferous forest) we have generated an improved evidence-base for the management of $P$. vernalis populations. We discuss these findings first, and then continue with the general implication for building conservation evidence on unpublished case studies, and other low-quality data reports.

\section{Nature conservation interventions to enforce Pulsatilla vernalis populations}

Our study supports an association between the vitality of $P$. vernalis populations and the occurrence of fire. Implementing fire as a conservation action increased the number of $P$. vernalis clusters. This does not necessarily mean that seedling regeneration is fire-dependent, but it does seem fire-favoured. Mechanical disturbance is often done as a substitute for fire (Granström 2001) but, based on the case studies included in our analysis, we cannot conclude that mechanical disturbance will have any positive effects on $P$. vernalis. Since burning in most cases were paved by a clearing of the bottom and field layer and since we found the effects of burning and mechanical disturbance to differ, we instead conclude that the positive effect of burning was related to more than the actual clearing. Therefore, mechanical disturbance cannot be regarded as equivalent to burning concerning $P$. vernalis. The positive effects of burning is probably explained by a delayed re-colonisation of competitors (Granström 2001; Kalamees et al. 2005; Schimmel \& Granström 1996) while changes in soil chemistry during burning involving, e.g. an increased $\mathrm{pH}$ and release of mineral nutrients, may also add qualities not shared with mechanical disturbance (Ahlgren 1960, Reyes et al. 2015, Gagnon et al. 2015). Burning, hence, seems central for the ongoing and future conservation work regarding long-term survival of the species. This is further indicated by the increased seeding and planting success of P. vernalis (Sandström 2013; Sandström et al. 2014) and the closely related P. patens (Kalamees et al. 2005) in burnt compared to mechanically cleared plots.

Furthermore, our study showed that the effect of burning on the number of clusters may be related to habitat type as there was a trend towards a higher increase in the number of clusters one year after burning within heathlands compared to within coniferous forests (it was not possible to compare for a longer time-period). 
The possible mechanisms involved are unclear, but the tree canopy might negatively affect regeneration in the forest. Another option might be that the competitors (mainly grasses and Calluna vulgaris) in the heathland might be denser, and hence their elimination by fire might give a more marked ecological release than that seen after a forest fire. A positive aspect of burning should be the delayed re-colonisation and growth of competitors (Kalamees et al. 2005; Schimmel \& Granström 1996). This would primarily enhance seedling survival, and not germination itself. Finally, it is possible that differences among habitat might be due to the amount and nature of combustible biomass, leading to fires of different intensity and/or to different edafic conditions.

We did find some positive effects by the interventions on flowering. However, as these were variable with shifting effect sizes and wide and overlapping confidence intervals they are difficult to interpret. When monitoring a large population in lowland Polen, Grzyl et al. (2014) recorded much larger variation in number of flowering shoots (coefficient of variation 50.0\%) than in number of clusters (18.1\%). As flowering in $P$. vernalis is affected by weather (also discussed and indicated in studies concerning other Pulsatilla species, e.g., Kalliovirta et al. 2006; Lindell 2001) interannual variation is likely to obscure treatment-driven patterns in flowering data making them less suitable for monitoring.

The growth form of $P$. vernalis complicates the monitoring of populations, as both rhizome- and seedoriginated rosettes are developed close to each other (the majority of the seeds sprout under the leaves of the rosettes; Kellner 1993). The plants thus display a dense appearance; compact clusters are generated and individual rosettes are hard to disentangle. These complications have probably led to the use of the total number of flowers or flowering clusters as inventory units in some case studies. Unfortunately, we consider changes in flowering and flowers being unreliable variables since a large part of the variation may depend on natural or undefined site-specific factors and weather, masking the effects of the different interventions. Including flowers as an inventory unit might illustrate the short-term vitality of the site but actual numeral changes seem less informative, the exception perhaps being when using control plants.

To sum up, best practice for conservation efforts would be burning. We also suggest that this could be done in combination with reinforcing existing populations through sowing or planting. A Polish study showed that natural regeneration from $P$. vernalis seeds in the field might be negligible (no seedlings or juvenile plants were found), despite plenty of flowering or fruiting plants (Grzyl \& Ronikier 2011) while populations have been successfully reinforced through sowing and planting (Betz et al. 2013). Furthermore we suggest using total number of clusters as the inventory unit as flowering data are less informative.

\section{Building conservation evidence on unpublished case-studies}

The used data sets were retrieved from previous and ongoing practical conservation work performed by conservationists throughout Sweden. Despite using data not primarily intended for scientific use, our study 
still provided important insights in the responsiveness of $P$. vernalis to different conservation actions. Hence, we believe there is potential in building conservation evidence through case studies. There is currently a journal (Conservation Evidence) devoted to documenting the outcome of interventions, often in the form of case studies (Spooner et al. 2015). Whether practitioners publish their findings is a matter of available time and resources and also a part of the traditions and culture of a workplace.

Even if $P$. vernalis might be exceptional in Sweden regarding the number of cases available, many other attempts to enhance habitats and populations of rare species have been conducted, or is in the planning phase, through the many Action Plans decided (e.g. Malmqvist et al. 2006; Ottvall 2016). Nevertheless, there are clear obstacles ahead. First of all, we need to involve practitioners in the process of building knowledge, so that records of interventions are properly documented. Second, there is a need for archiving such records. Third, it is apparent from our study that a large proportion of interventions conducted did not fulfil our basic quality criteria. Hence, much could be gained if there were guidelines developed for a number of typical scenarios on how to document interventions.

Insufficient documentation during practical conservation work is an already known problem inhibiting evaluation of conservation projects (Milberg \& Bergman 2010; Sutherland et al. 2004). Apart from proper and standardised inventory protocols, the time period and frequency of the conducted inventories are essential for evaluating the effects of conservation interventions. Doing accurate follow-ups is crucial but often found incomplete or absent (Milberg \& Bergman 2010; Sutherland et al. 2004). The reason for this seems, to us, to be a lack of both time and resources. An increased and more structured, easy-accessible documentation would provide a larger data set and improve both the quantity and quality of future systematic reviews (Milberg \& Bergman 2010).

A keystone within meta-analyses is the ability to weigh how much influence the outcome of each individual study should have on the final overall effect size. As is often the case, also in our study on Pulsatilla vernalis, individual experiments often rely on small sample sizes, and therefore have low statistical power (Harrison 2011). The weighing is based on the variance within each study which imply that each study is based on a number of replicates. The majority of case studies in our study, however, lacked replicates within the sites and thus prevented us from using the standardised mean difference, which is the most common measure of effect size (Harrison 2011). The presence of replicates would have required a monitoring of $P$. vernalis subpopulations and replicating the intervention over subpopulations. But as most populations are small, that would not have been possible. Rather, when working with species in small populations, replication need to be between, not within, sites. To overcome this obstacle we used the effect sizes event rate and odds ratio, with some adjustments. By doing this, individual case studies could be weighed and effect sizes calculated (Borenstein et al. 2009). These adjustments are, however, subject to potential statistical critique. Event rate and odds ratio are both based on two groups, non-events vs. events and control vs. treatment, respectively, and we interpreted these as before and after the intervention. However, before 
and after data are not independent, something the two models do not consider. The potential effects of this are unclear and would need further study. Nonetheless, using independent case studies with both a spatial and temporal distribution served to compensate for the natural variation and the overall outcome should reflect the impact of the intervention.

\section{Different levels of evidence in data collected}

In ecology, and consequently also in conservation biology, there is a tendency for considering only scientific experiments when assessing the evidence for a particular treatment. Such results mean high level of evidence that is well-documented and easily available. In contrast, ecologists seem more sceptical towards observational studies and down-right negative towards case studies. Even if case studies might not advance science much - if at all - we like to believe that many case studies put together help build an evidence-base for decision support. Within the medical field, there would have been very little advance if only welldesigned experiments were published. Instead, depending on circumstances, a whole range of study design are acceptable; the Cochrane Collaboration (Higgins \& Green 2016) lists a dozen (Randomized controlled trial, Quasi-randomized controlled trial; Non-randomized controlled trial; Controlled before-and-after study; Prospective cohort study; Retrospective cohort study; Historically controlled trial; Nested case-control study; Case-control study; Cross-sectional study; Before-and-after comparison; Case report/Case series). It is noteworthy that comparisons of effect sizes recorded in study design considered better or worse rarely show systematic differences (e.g. Golder et al. 2011). Hence, we think it is high time for researchers within applied ecology to adopt a more diversified view on "evidence", similar to that prevailing within medicine (Burns et al. 2011), thus allowing for decision support to accumulate at a much higher rate than at present.

\section{Acknowledgements}

We thank all the informants for taking time to provide information about their conservation actions across the different sites of Pulsatilla vernalis. This study would not have been possible without their help and devotion for $P$. vernalis. The study was financially supported by the Department of Biology Education at Uppsala University. 


\section{References}

Agrawal, D. (2005). Inappropriate interpretation of the odds ratio: oddly not that uncommon. Pediatrics, $116,1612-1613$.

Ahlgren, C. E. (1960). Some effects of fire on reproduction and growth of vegetation in northeastern Minnesota. Ecology, 41, 431-445.

ArtDatabanken (2015). Rödlistade arter i Sverige 2015. ArtDatabanken, SLU, Uppsala. In Swedish with English summary.

Åström, S., \& Stridh, B. (2003). Mosippa: årets växt 2002. Svensk Botanisk Tidskrift, 97, 117-126. In Swedish.

Betz, C., Scheuerer, M., \& Reisch, C. (2013). Population reinforcement: A glimmer of hope for the conservation of the highly endangered Spring Pasque flower (Pulsatilla vernalis). Biological Conservation, 168, 161-167.

Borenstein, M., Hedges, L. V., Higgins, J. P. T., \& Rothstein, H. R. (2009). Introduction to meta-analysis. West Sussex: John Wiley \& Sons Ltd,

Burns, P. B., Rohrich, R. J., \& Chung, K. C. (2011). The levels of evidence and their role in evidence-based medicine. Plastic and Reconstructive Surgery, 128, 305-310.

Gagnon, P. R., Passmore, H. A., Slocum, M., Myers, J. A., Harms, K. E., Platt, W. J., \& Paine, C. E. (2015). Fuels and fires influence vegetation via above-and belowground pathways in a high-diversity plant community. Journal of Ecology, 103, 1009-1019.

Gates, S. (2002). Review of methodology of quantitative reviews using meta-analysis in ecology. Journal of Animal Ecology, 71, 547-557.

Golder, S., Loke, Y. K., \& Bland, M. (2011). Meta-analyses of adverse effects data derived from randomised controlled trials as compared to observational studies: methodological overview. PLoS Medicine 8, p.e1001026.

Granström, A. (2001). Fire management for biodiversity in the European boreal forest. Scandinavian Journal of Forest Research, 16, 62-69.

Grzyl, A., \& Ronikier, M. (2011). Pulsatilla vernalis (Ranunculaceae) in the Polish lowlands: current population resources of a declining species. Polish Botanical Journal, 56, 185-194.

Grzyl, A., Niewiadomski, A., \& Woziwoda, B. (2013). Soil environment of Pulsatilla vernalis (L.) Mill. at selected sites in the Polish lowland. Acta Societatis Botanicorum Poloniae, 82, 267-273. 
Grzyl, A., Kiedrzynski, M., Zielinska, K. M., \& Rewicz, A. (2014). The relationship between climatic conditions and generative reproduction of a lowland population of Pulsatilla vernalis: the last breath of a relict plant or a fluctuating cycle of regeneration? Plant Ecology, 215, 457-466.

Gurevitch, J., \& Hedges, L. V. (1999). Statistical issues in ecological meta-analyses. Ecology, 80, 11421149.

Harrison, F. (2011). Getting started with meta-analysis. Methods in Ecology and Evolution, 2, 1-10.

Hedwall, P. O., Brunet, J., Nordin, A., \& Berg, J. (2013). Changes in the abundance of keystone forest floor species in response to changes of forest structure. Journal of Vegetation Science, 24, 296-306.

Higgins, J. P. T., \& Green, S. (2016). Cochrane handbook for systematic reviews of interventions. Version 5.1.0. http://handbook.cochrane.org/ (accessed August 2016).

Hultén, E., \& Fries, M. (1986). Atlas of North European vascular plants: north of the Tropic of Cancer I-III. Koeltz Scientific Books, Königstein.

Kalamees, R., Püssa, K., Vanha-Majamaa, I., \& Zobel, K. (2005). The effects of fire and stand age on seedling establishment of Pulsatilla patens in a pine-dominated boreal forest. Canadian Journal of Botany, 83, 688-693.

Kalliovirta, M., Ryttäri, T., \& Heikkinen, R. K. (2006). Population structure of a threatened plant, Pulsatilla patens, in boreal forests: modelling relationships to overgrowth and site closure. Biodiversity and Conservation, 15, 3095-3108.

Kellner, O. (1993). Effects of nitrogen addition on the population dynamics and flowering of Pulsatilla vernalis. Canadian Journal of Botany, 71, 732-736.

Koricheva, J., Gurevitch, J., \& Mengersen, K. (Eds), (2013). Handbook of meta-analysis in ecology and evolution. Princeton University Press, Princeton and Oxford.

Lindell, T. (2001). Pulsatilla. In: Jonsell, B. (Ed), Flora Nordica Vol. 2, pp 305-307. The Bergius Foundation, Stockholm.

Malmqvist, A., Andersson, R., Arup, U., Nilsson, S. G., \& Svensson, S. (2006). Åtgärdsprogram för bevarande av sex hotade bokskogsarter. Naturvårdsverket, Rapport 5553, 60 pp.

http://www.naturvardsverket.se/Documents/publikationer/620-5553-4.pdf?pid=3174 In Swedish with English summary.

Milberg, P. (2014). Evidence-based vegetation management: prospects and challenges. Applied Vegetation Science, 17, 604-608. 
Milberg, P., \& Bergman, K.-O. (2010). Evidensbaserad naturvård: nytt begrepp och ny färdriktnig? Svensk Botanisk Tidskrift, 104, 18-22. In Swedish with English summary.

Ottvall, R. (2016). Åtgärdsprogram för hotade vadare på strandängar. Naturvårdsverket, Rapport 6680, 54 p. http://www.naturvardsverket.se/Documents/publikationer6400/978-91-620-6680-2.pdf?pid=15518 In Swedish with English summary.

Pullin, A. S., \& Knight, T. M. (2003). Support for decision making in conservation practice: an evidencebased approach. Journal for Nature Conservation, 11, 83-90.

Pullin, A. S., \& Stewart, G. B. (2006). Guidelines for systematic review in conservation and environmental management. Conservation Biology, 20, 1647-1656.

Reyes, O., Kaal, J., Aran, D., Gago, R., Bernal, J., Garcia-Duro, J., \& Basanta, M. (2015). The effects of ash and black carbon (biochar) on germination of different tree species. Fire Ecology, 11, 119-133.

Ronikier, M., Costa, A., Aguilar, J. F., Feliner, G. N., Küpfer, P., \& Mirek, Z. (2008). Phylogeography of Pulsatilla vernalis (L.) Mill. (Ranunculaceae): chloroplast DNA reveals two evolutionary lineages across central Europe and Scandinavia. Journal of Biogeography, 35, 1650-1664.

Sandström, A. (2013). Management of Pulsatilla vernalis in Sweden using an evidence-based perspective. MSc thesis, Institutionen för biologisk grundutbildning, Uppsala University.

Sandström, A., Milberg, P., \& Svensson B. M. (2014). Har tidigare åtgärder för att stärka mosippan varit effektiva? Ett steg mot evidensbaserad naturvård i Sverige. Svensk Botanisk Tidskrift, 108, 26-33. In Swedish with English summary.

Schimmel, J., \& Granström, A. (1996). Fire severity and vegetation response in the boreal Swedish forest. Ecology, 77, 1436-1450.

Spooner, F., Smith, R. K, \& Sutherland, W. J. (2015). Trends, biases and effectiveness in reported conservation interventions. Conservation Evidence, 12, 2-7.

Ståhl, P., \& Edqvist, M. (2006). Pulsatilla vernalis - mosippa. http://artfakta.artdatabanken.se/taxon/1853. Date visited 15 May 2015. ArtDatabanken, Uppsala, Sweden. In Swedish.

Stewart, G. B., Coles, C. F., \& Pullin, A. S. (2005). Applying evidence-based practice in conservation management: Lessons from the first systematic review and dissemination projects. Biological Conservation, 126, 270-278.

Stewart, G. B., Bayliss, H. R., Showler, D. A., Sutherland, W.J., \& Pullin, A. S. (2009). Effectiveness of engineered in-stream structure mitigation measures to increase salmonid abundance: a systematic review. Ecological Applications, 19, 931-941. 
Stridh, B., Granström, A., \& Sallmén, N. (2016). Åtgärdsprogram för mosippa 2016-2020. Naturvårdsverket. Rappport 6726, 51 pp. In Swedish with English summary.

http://www.naturvardsverket.se/Documents/publikationer6400/978-91-620-6726-7.pdf?pid=19108

Sutherland, W. J. Pullin, A. S., Dolman, P. M., \& Knight, T. M. (2004). The need for evidence-based conservation. Trends in Ecology and Evolution, 19, 305-308.

Thompson, S. G., \& Higgins, J. P. T. (2002). How should meta-regression analyses be undertaken and interpreted? Statistics in Medicine, 21, 1559-1573.

Zielińska, K. M., Kiedrzyński, M., Grzyl, A., \& Rewicz, A. (2016). Forest roadsides harbour less competitive habitats for a relict mountain plant (Pulsatilla vernalis) in lowlands. Scientific Reports, 6, 31913. 
Table 1. Changes in flowering attributes of Pulsatilla vernalis after intervention (burning or mechanical). Units are logit event rates (mean $\pm \mathrm{CI}_{95 \%}$ ), or odds ratio ( $\pm \mathrm{CI}_{95 \%}$ ), with positive effect sizes indicating an increase after the intervention and vice versa. $\mathrm{N}$ is the number of cases included. P-values evaluate the null hypothesis that the intervention had no effect.

Number of flowering clusters

Mechanical disturbance

Proportion of flowering clusters

Burning

Mechanical disturbance

Number of flowers

Burning

Mechanical disturbance
CI95\%

logit ER

1st yr 1.421

1 st yr $\quad 0.21$

$-0.385 ; 0.805$

$8 \quad 0.489$

$\log \mathrm{OR}$

$-0.462 ; 1.738 \quad 2$

0.239

$\begin{array}{lllll}1 \text { st yr } & 0.373 & -0.827 ; 1.573 & 7 & 0.526\end{array}$

Logit ER

$\begin{array}{lllll}1 \text { st yr } & -2.398 & -5.293 ; 0.497 & 1 & 0.105\end{array}$

2nd

$\begin{array}{lllll}\text { yr } & 1.386 & -0.805 ; 3.578 & 1 & 0.215\end{array}$

$\begin{array}{lllll}1 \text { st yr } & -0.495 & -1.585 ; 0.595 & 4 & 0.374\end{array}$

2nd

$\begin{array}{lllll}\text { yr } & -0.064 & -2.067 ; 1.939 & 3 & 0.950\end{array}$ 
Figure legend

Figure 1. Process scheme for finding, evaluating and compiling data from interventions to promote populations of Pulsatilla vernalis in Sweden.

Figure 2. Change in number of Pulsatilla vernalis clusters after intervention (burning or mechanical). Units are logit event rates (mean $\pm \mathrm{CI}_{95 \%}$ ), with positive effect size indicating an increase in $P$. vernalis after the intervention and vice versa. 1a. Changes per case, combining both intervention types and records over 1-3 yrs and weight of each case (\%) for the overall outcome. 1b. Change per intervention and year (number of cases); change also expressed in percent to the right. 1c. Change in burnt plots after one year, grouped by habitat type (number of cases); change also expressed in percent to the right. 

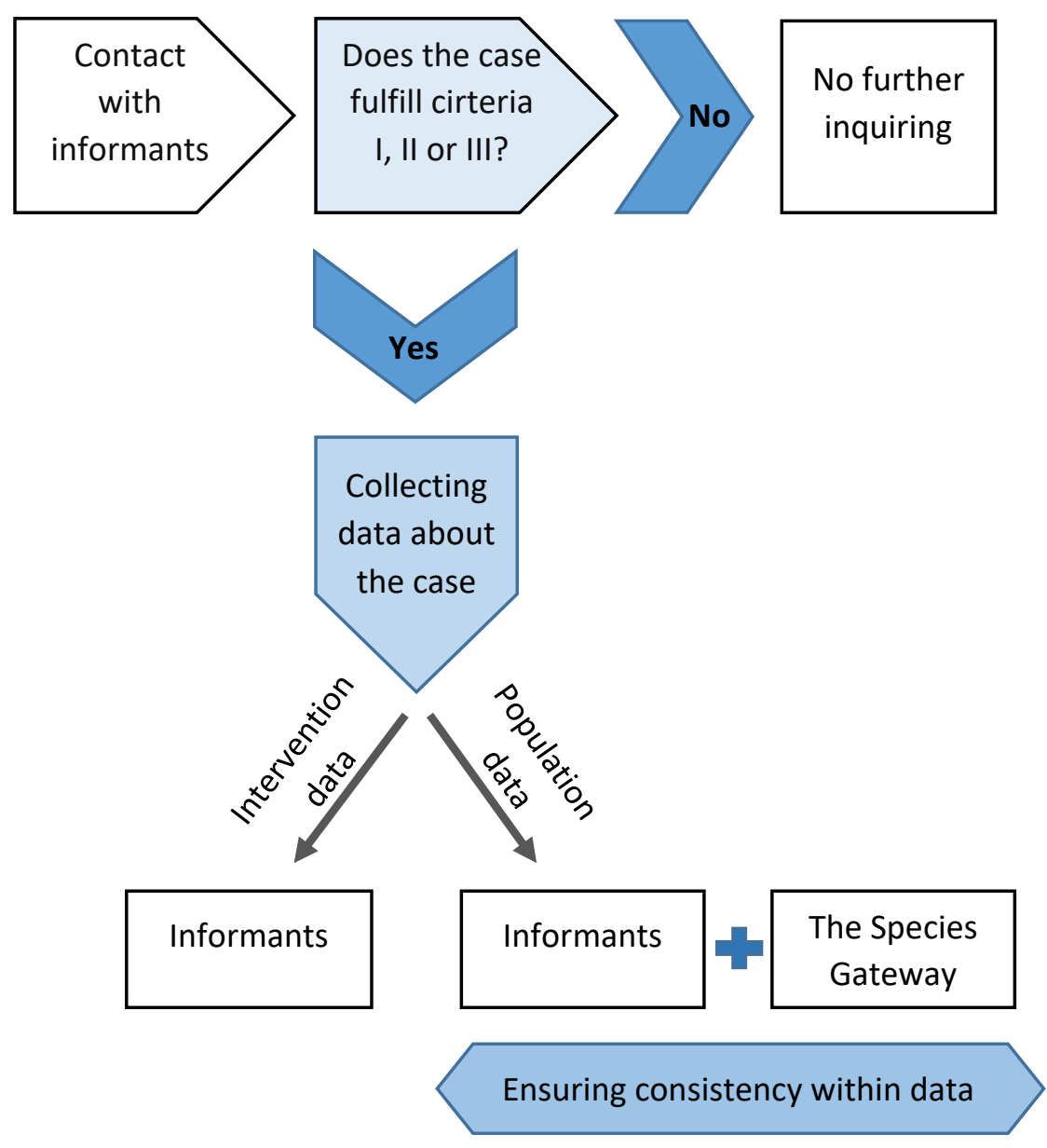
Overall change in individual cases $(\mathrm{N}=19)$; and the weight of cases in analyses

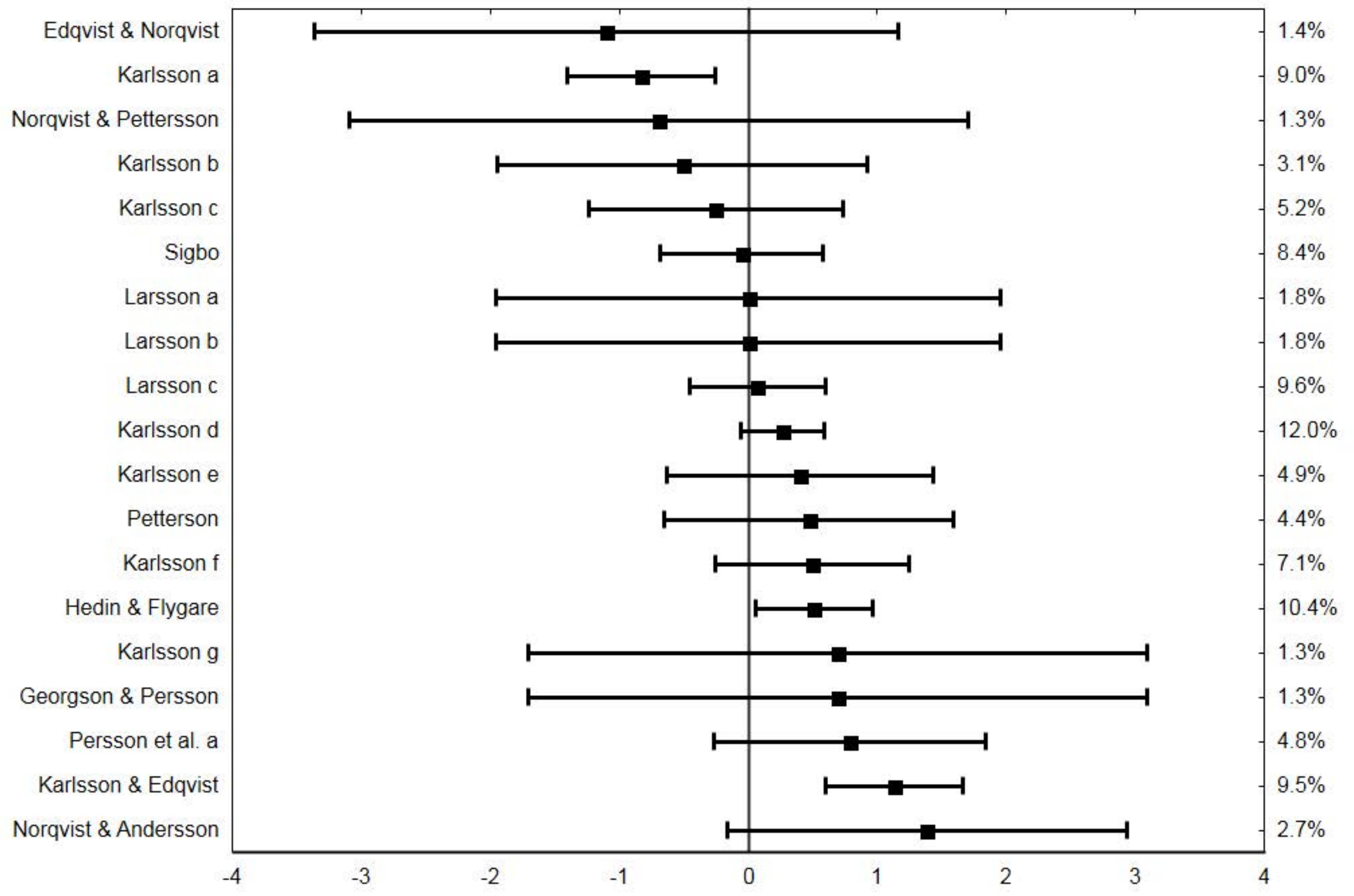


Contrasting two intervention types after 1,2 and 3 years

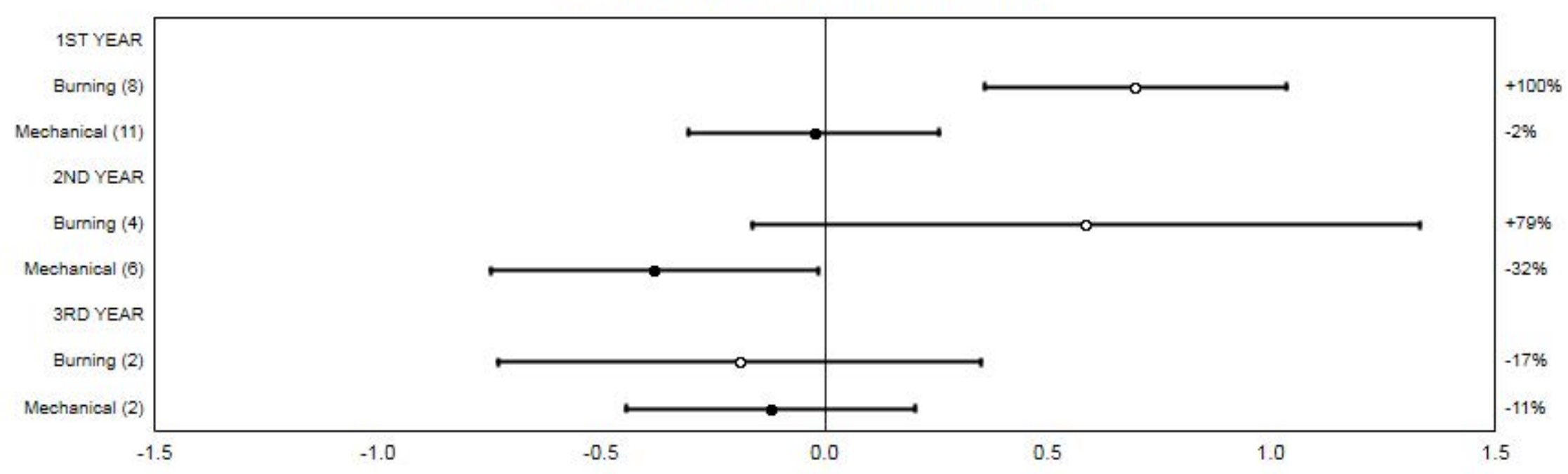


